\title{
Sex/Gender Research and Meta-Analysis
}

\author{
Kenneth J. Zucker ${ }^{1}$
}

Published online: 5 February 2020

(c) Springer Science+Business Media, LLC, part of Springer Nature 2020
I have always been fond of numbers, statistics, and mathematics although I am not very good at the latter two. As a child, with my friends, we created a "a league of our own" baseball world, inventing what we called "dice baseball" and kept copious statistics of our competitions. Hence, it is no wonder that I very much liked the 2011 film Moneyball, starring Brad Pitt (https://en.wikipedia.org/wiki/Moneyball_(film)).

Near the end of my graduate school days, I dimly recall the emergence of meta-analysis as an alternative to narrative reviews (Glass, McGaw, \& Smith, 1981). Indeed, meta-analysis has become exceedingly important in the world of quantitative science. As of January 21, 2020, a PubMed search of "meta-analysis" yields a mere 176,759 hits. After publishing a narrative review on a topic related to my doctoral dissertation (Zucker, 1985), I realized my inadequacies and that I needed to get with it.

But it wasn't until the mid-1990s that I had the opportunity to collaborate with Michael Bailey on my first meta-analytic adventure (Bailey \& Zucker, 1995). According to Google Scholar, it has been cited 836 times. ${ }^{1}$ Not bad. Subsequently, I have had the privilege and good fortune to publish two other meta-analytic studies (Grimbos, Dawood, Burris, Zucker, \& Puts, 2010; Lalumière, Blanchard, \& Zucker, 2000) with colleagues and another one is in the works (Zucker \& Aitken, 2018). ${ }^{2}$

Given my fondness for meta-analysis, I am delighted that the first four articles in this issue are meta-analytic studies (Collaer \& Hines, 2020; Davis \& Hines, 2020; Sadr, Khorashad, Talaei, Fazeli, \& Hönekopp, 2020; Xu, Norton, \& Rahman, 2020). Since I became Editor of the Journal in 2002, we

Kenneth J. Zucker

ken.zucker@utoronto.ca

1 Department of Psychiatry, University of Toronto, Toronto, ON M5T 1R8, Canada have published at least 19 other meta-analytic papers (Babchishin, Hanson, \& VanZuylen, 2015; Babchishin, Nunes, \& Hermann, 2013; Blanchard, 2018; Blanchard \& VanderLaan, 2015; Chivers, Seto, Lalumière, Laan, \& Grimbos, 2010; Ferguson \& Malouff, 2016; Frühauf, Gerger, Munder, Schmidt, \& Barth, 2013; Grubbs, Perry, Wilt, \& Reid, 2019; Karamouzian, Nasirian, Hoseini, \& Mirzazadeh, 2019; Kettrey \& Marx, 2019; Newcomb \& Mustanski, 2011; Polisois-Keating \& Joyal, 2013; Przybyla, Krawiec, Godleski, \& Crane, 2018; Puts, McDaniel, Jordan, \& Breedlove, 2008; Rooney, Tulloch, \& Blashill, 2018; Salway et al., 2019; Schmidt, Babchishin, \& Lehmann, 2017; Van Dongen, 2012; Zou \& Fan, 2017) and at least two more are in press (Körner, Schaper, Pause, \& Heil, in press; Mori et al., in press).

It gives me great pleasure that the Journal has become a regular repository of meta-analytic work on topics pertaining to sex/gender. I look forward to publishing more of them. They are an essential aspect of advancing the field of sex/gender science.

\footnotetext{
$\overline{1}$ https://scholar.google.ca/citations?user=X_pBW6QAAAAJ $\&$ hl=en.

2 At the time, I told Bailey that the relationship between sex-typed behavior in childhood and sexual orientation in adulthood needed to be documented systematically. Although the relationship was obvious to me based on the retrospective and prospective literature, back in the day, I knew it would annoy a lot of people to demonstrate it systematically via meta-analysis. That it did. Now, no one cares. As a graduate student, Grimbos came to me and said that she wanted to do some readings as part of an independent course. I said, more or less, "That's boring. Let's do a meta-analysis." We learned that Puts and colleagues were doing a similar meta-analysis, so we joined forces (that's called collaboration and collegiality). When Lalumière told me that he wanted to do a meta-analysis on sexual orientation and handedness, I told him I would provide him with all of the relevant studies, but that he would find nothing. I was wrong.
} 


\section{References}

Babchishin, K. M., Hanson, R. K., \& VanZuylen, H. (2015). Online child pornography offenders are different: A meta-analysis of the characteristics of online and offline sex offenders against children. Archives of Sexual Behavior, 44, 45-66.

Babchishin, K. M., Nunes, K. L., \& Hermann, C. A. (2013). The validity of Implicit Association Test (IAT) measures of sexual attraction to children: A meta-analysis. Archives of Sexual Behavior, 42, 487-499.

Bailey, J. M., \& Zucker, K. J. (1995). Childhood sex-typed behavior and sexual orientation: A conceptual analysis and quantitative review. Developmental Psychology, 31, 43-55.

Blanchard, R. (2018). Fraternal birth order, family size, and male homosexuality: Meta-analysis of studies spanning 25 years. Archives of Sexual Behavior, 47, 1-15.

Blanchard, R., \& VanderLaan, D. P. (2015). Commentary on Kishida and Rahman (2015), including a meta-analysis of relevant studies on fraternal birth order and sexual orientation in men [Invited Commentary]. Archives of Sexual Behavior, 44, 1503-1509.

Chivers, M. L., Seto, M. C., Lalumière, M. L., Laan, E., \& Grimbos, T. (2010). Agreement of self-reported and genital measures of sexual arousal in men and women: A meta-analysis. Archives of Sexual Behavior, 39, 5-56.

Collaer, M. T., \& Hines, M. (2020). No evidence for enhancement of spatial ability with elevated prenatal androgen exposure in congenital adrenal hyperplasia: A meta-analysis. Archives of Sexual Behavior. https://doi.org/10.1007/s10508-020-01645-7.

Davis, J. T. M., \& Hines, M. (2019). How large are gender differences in toy preferences? A systematic review and meta-analysis of toy preference research. Archives of Sexual Behavior. https://doi. org/10.1007/s10508-019-01624-7.

Ferguson, C. E., \& Malouff, J. M. (2016). Assessing police classifications of sexual assault reports: A meta-analysis of false reporting rates. Archives of Sexual Behavior, 45, 1185-1193.

Frühauf, S., Gerger, H., Munder, T., Schmidt, H., \& Barth, J. (2013). Efficacy of psychological interventions for sexual dysfunction: A systematic review and meta-analysis. Archives of Sexual Behavior, 42, 915-933.

Glass, G. V., McGaw, B., \& Smith, M. L. (1981). Meta-analysis in social research. Newbury Park, CA: Sage Publications.

Grimbos, T., Dawood, K., Burris, R., Zucker, K. J., \& Puts, D. A. (2010). Sexual orientation and the second to fourth finger length ratio: A meta-analysis in men and women. Behavioral Neuroscience, 124, 278-287.

Grubbs, J. B., Perry, S. L., Wilt, J. A., \& Reid, R. C. (2019). Pornography problems due to moral incongruence: An integrative model with a systematic review and meta-analysis. Archives of Sexual Behavior, 48, 397-415.

Karamouzian, M., Nasirian, M., Hoseini, S. G., \& Mirzazadeh, A. (2019). HIV and other sexually transmitted infections among female sex workers in Iran: A systematic review and meta-analysis. Archives of Sexual Behavior. https://doi.org/10.1007/s10508-019-01574-0.

Kettrey, H. H., \& Marx, R. A. (2019). Does the gendered approach of bystander programs matter in the prevention of sexual assault among adolescents and college students? A systematic review and meta-analysis. Archives of Sexual Behavior, 48, 2037-2053.

Körner, L. M., Schaper, M. L., Pause, B. M., \& Heil, M. (in press). Parent-reports of sex-typed play preference in preschool children:
Relationships to 2D:4D digit ratio and older siblings' sex. Archives of Sexual Behavior.

Lalumière, M. L., Blanchard, R., \& Zucker, K. J. (2000). Sexual orientation and handedness in men and women: A meta-analysis. Psychological Bulletin, 126, 575-592.

Mori, C., Cooke, J. E., Temple, J. R., Ly, A., Lu, Y., Anderson, N., ... Madigan, S. (in press). The prevalence of sexting behaviors among emerging adults: A meta-analysis. Archives of Sexual Behavior.

Newcomb, M. E., \& Mustanski, B. (2011). Moderators of the relationship between internalized homophobia and risky sexual behavior in men who have sex with men: A meta-analysis. Archives of Sexual Behavior, 40, 189-199.

Polisois-Keating, A., Christian, C., \& Joyal, C. C. (2013). Functional neuroimaging of sexual arousal: A preliminary meta-analysis comparing pedophilic to non-pedophilic men [Letter to the Editor]. Archives of Sexual Behavior, 42, 1111-1113.

Przybyla, S. M., Krawiec, G., Godleski, S. A., \& Crane, C. A. (2018). Meta-analysis of alcohol and serodiscordant condomless sex among people living with HIV. Archives of Sexual Behavior, 47, 1351-1366.

Puts, D. A., McDaniel, M. A., Jordan, C. L., \& Breedlove, S. M. (2008). Spatial ability and prenatal androgens: Meta-analyses of congenital adrenal hyperplasia and digit ratio (2D:4D) studies. Archives of Sexual Behavior, 37, 100-111.

Rooney, B. M., Tulloch, T. G., \& Blashhill, A. J. (2018). Psychosocial syndemic correlates of sexual compulsivity among men who have sex with men: A meta-analysis. Archives of Sexual Behavior, 47, $75-93$.

Sadr, M., Khorashad, B. S., Talaei, A., Fazeli, N., \& Hönekopp, J. (2020). 2D:4D suggests a role of prenatal testosterone in gender dysphoria. Archives of Sexual Behavior. https://doi.org/10.1007/ s10508-020-01630-0.

Salway, T., Ross, L. E., Fehr, C. P., Burley, J., Asadi, S., Hawkins, B., \& Tarasoff, L. A. (2019). A systematic review and meta-analysis of disparities in the prevalence of suicide ideation and attempt among bisexual populations. Archives of Sexual Behavior, 48, 89-111.

Schmidt, A. F., Babchishin, K. M., \& Lehmann, R. J. B. (2017). A metaanalysis of viewing time measures of sexual interest in children. Archives of Sexual Behavior, 46, 287-300.

Van Dongen, S. (2012). Fluctuating asymmetry and masculinity/femininity in humans: A meta-analysis. Archives of Sexual Behavior, 41, 1453-1460.

Xu, Y., Norton, S., \& Rahman, Q. (2020). Sexual orientation and cognitive ability: A multivariate meta-analytic follow-up. Archives of Sexual Behavior. https://doi.org/10.1007/s10508-020-01632-y.

Zou, H., \& Fan, S. (2017). Characteristics of men who have sex with men who use smartphone geosocial networking applications and implications for HIV interventions: A systematic review and metaanalysis. Archives of Sexual Behavior, 46, 885-894.

Zucker, K. J. (1985). The infant's construction of his parents in the first six months of life. In T. M. Field \& N. A. Fox (Eds.), Social perception in infants (pp. 127-156). Norwood, NJ: Ablex Publishing Corporation.

Zucker, K. J., \& Aitken, M. (2018). Sex ratio of transgender adolescents: A meta-analysis. Paper presented at the meeting of the International Academy of Sex Research, Madrid, Spain.

Publisher's Note Springer Nature remains neutral with regard to jurisdictional claims in published maps and institutional affiliations. 